\title{
əDirect and Indirect Effects of Surface Fluxes on Moist Baroclinic Development in an Idealized Framework
}

\author{
KRISTINE F. HAUALAND AND ThOMAS SPENGLER \\ Geophysical Institute, University of Bergen, and Bjerknes Centre for Climate Research, Bergen, Norway
}

(Manuscript received 2 December 2019, in final form 16 July 2020)

\begin{abstract}
The convoluted role of surface sensible and latent heat fluxes on moist baroclinic development demands a better understanding to disentangle their local and remote effects. Including diabatic effects in the Eady model, the direct effects of surface fluxes on the diabatic generation of eddy available potential energy as well as their indirect effects through modifications of the circulation and latent heating are investigated. It is shown that surface sensible heat fluxes have a minor impact, irrespective of their position and parameterization, while latent heating in the region equivalent to the warm conveyor belt is the dominant diabatic source for development. Downward surface sensible heat fluxes in proximity of the warm conveyor belt results in structural modifications that increase the conversion from basic-state available potential energy to eddy available potential energy, while concomitantly weakening the ascent and hence latent heating. The detrimental effects are easily compensated through provision of additional moisture into the warm conveyor belt. Upward surface heat fluxes in the cold sector, on the other hand, are detrimental to growth. When downward (upward) surface sensible heat fluxes are located below the equivalent of the warm conveyor belt, the diabatically induced PV anomaly at the bottom of the latent heating layer becomes dominant (less dominant). Shifting the downward surface sensible heat fluxes away from the warm conveyor belt results in substantial changes in the growth rate, latent heat release, lowlevel structure, and energetics, where the effect of surface sensible heat fluxes might even be beneficial.
\end{abstract}

\section{Introduction}

The influence of surface sensible and latent heat fluxes on midlatitude cyclone development is uncertain and varies with environmental conditions in the atmosphere and ocean (e.g., Nuss and Anthes 1987; Kuo and Reed 1988; Mullen and Baumhefner 1988). Nuss and Anthes (1987) found that the effect of surface fluxes varies from reducing the growth rate of extratropical cyclones by $25 \%$ to enhancing it by $15 \%$. Moreover, when cyclones move over regions with different air-sea temperature contrasts, the role of surface fluxes often changes substantially during the development (Kuo et al. 1991a) and may even reverse or partially cancel (Langland et al. 1995). With state-of-the-art numerical weather prediction models still struggling to correctly represent the amount and

Denotes content that is immediately available upon publication as open access. location of diabatic processes in cyclone development (e.g., Schäfler et al. 2018) as well as climate models featuring significant biases in sea surface temperatures resulting in a misrepresentation of storm tracks (e.g., Keeley et al. 2012; Lee et al. 2018), improving our understanding of the influence of surface fluxes on cyclone development will allow us to identify associated sources of model biases and forecast uncertainties.

While surface latent heat fluxes are usually upward in most parts of the cyclone (e.g., Carrera et al. 1999; Zhang et al. 1999), surface sensible heat fluxes often feature a dipole with upward fluxes in the cold sector and downward fluxes in the warm sector of the cyclone (e.g., Danard and Ellenton 1980; Fleagle and Nuss 1985; Neiman and Shapiro 1993; Sinclair et al. 2010; Booth et al. 2012). Such a distribution of surface sensible heat fluxes can reduce low-level baroclinicity (Branscome et al. 1989; Zhang and Stone 2011) and ascent in the

This article is licensed under a Creative Commons Attribution 4.0 license (http://creativecommons.org/ licenses/by/4.0/).

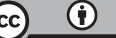

Corresponding author: Kristine Flacké Haualand, kristine. haualand@uib.no 
warm sector of the cyclone (Kuo et al. 1991a), potentially weakening cyclone growth (Haltiner 1967; Kuo and Low-Nam 1990).

Under different environmental conditions, however, surface sensible heat fluxes can also be upward in the warm sector. For example, during the early phase of an explosive midlatitude cyclone studied by Kuo et al. (1991a), polar air from a previous cold-air outbreak resulted in upward surface sensible heat fluxes in the warm sector. When excluding these fluxes in numerical simulations of the storm, the cyclone development was considerably weaker. This impact from surface fluxes is supported by the climatological study by Gyakum and Danielson (2000), where the strongest cyclogenesis was associated with cold air downstream of the developing cyclone in conjunction with higher sea surface temperatures and thereby larger surface fluxes. Furthermore, strong upward oceanic surface fluxes warmed, moistened, and destabilized the cold boundary layer of the vigorous Presidents' Day snowstorm, resulting in a strong lowlevel baroclinic zone that aided cyclone development at an early stage (Bosart 1981). Thus, under certain conditions, surface sensible heat fluxes can enhance, rather than weaken, low-level baroclinicity while reducing static stability (Reed and Albright 1986; Atlas 1987; Carrera et al. 1999), yielding favorable conditions for cyclone intensification.

Another contribution to cyclone growth is associated with surface latent heat fluxes that moisten the air in the boundary layer (Mailhot and Chouinard 1989). Combining this effect with a reduced static stability can lead to substantially enhanced latent heating and cyclone growth (Uccellini et al. 1987; Nuss and Anthes 1987; Carrera et al. 1999; Hirata et al. 2019). Zhang et al. (1999) stressed the importance of this moist effect on midlatitude cyclone development and found the impact of surface heat fluxes only to be significant when latent heating was included in the numerical experiments. As latent heating strongly intensifies and alters cyclone development (e.g., Craig and Cho 1988; Kuo et al. 1991b; Balasubramanian and Yau 1996), the influence of surface fluxes should be studied in conjunction with latent heating.

Investigating both of these diabatic effects in baroclinic life cycle experiments using a primitive equation global spectral model, Gutowski and Jiang (1998) found that surface heat fluxes destabilize the cold sector and stabilize the warm sector, resulting in a shift of convective heating to the cold sector. Consequently, in a follow-up study including constant surface sensible heat fluxes, Jiang and Gutowski (2000) examined the effect of convective heating only above the cold sector. While surface fluxes can indeed modify the convective heating in the cold sector, the impact on the warm conveyor belt, where most of the latent heating occurs (Browning 1990), is probably more crucial for the development of the storm.

To investigate the role of surface fluxes in a framework that includes latent heating in the warm conveyor belt, we use the numerical extension of Mak's (1994) 2D quasigeostrophic (QG) linear model that was introduced by Haualand and Spengler (2019, hereafter HS19). This model is based on the Eady (1949) model and includes latent heating proportional to low-level vertical motion. Here, we further extend the model with different parameterizations of surface sensible heat fluxes based on either air-sea temperature differences (similar to Mak 1998), warm-air advection, or the location and intensity of the warm conveyor belt and investigate the impact of varying their intensity and location on the growth rate, structure, and energetics of the baroclinic wave in the presence of latent heating. We focus on the incipient stage of midlatitude cyclones, as later stages are typically highly nonlinear (e.g., Kuo et al. 1991b) and therefore inadequately represented by our linear model.

While surface sensible heat fluxes directly affect baroclinic development by altering the diabatic generation of eddy available potential energy, surface sensible and latent heat fluxes can also indirectly influence baroclinic development through changes in the circulation and moisture supply. For example, Boutle et al. (2010), Pfahl et al. (2014), and Dacre et al. (2019) found that surface latent heat fluxes remote from the cyclone area strongly control the input of moisture into the warm conveyor belt and hence the latent heat release. To examine and quantify this indirect effect of surface latent heat fluxes, we vary the latent heating intensity to evaluate the sustained surface latent heat fluxes needed to provide the additional moisture supply to the warm conveyor belt to overcome the detrimental effects from local surface sensible heat fluxes.

\section{Model}

\section{a. Basic equations and model setup}

We extend the linear 2D QG model formulated by Mak (1994) and HS19, which includes different diabatic forcings in the Eady (1949) model, by implementing various formulations of surface sensible heat fluxes. Following Mak (1994), we use pressure as the vertical coordinate and assume wavelike solutions in the $x$ direction for the QG streamfunction $\psi$ and vertical motion $\omega$ : 


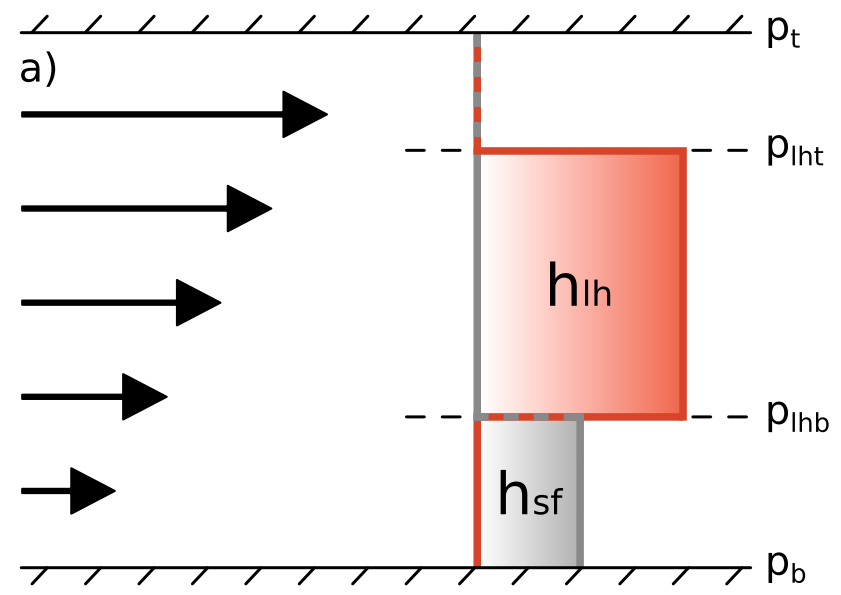

b)

FIG. 1. Schematic of (a) the linearly increasing zonal wind with decreasing pressure (black arrows) and vertical profiles of latent heating (red) and surface fluxes (gray) and (b) vertical and zonal locations of downward surface sensible heat fluxes relative to the area of latent heating for the formulations based on $T_{s}[(8)$, red $], v_{s}\left[(9)\right.$, blue], and $\omega_{*}[(11)$, gray]. Black dashed lines in (a) indicate heating boundaries where internal diabatically produced PV can form. Gray dot-dashed and dashed lines in (b) respectively indicate the location of the surface fluxes based on a $+90^{\circ}$ and $-90^{\circ}$ zonal phase shift relative to $\omega_{*}$.

$$
[\psi, \omega]=\operatorname{Re}\{[\hat{\psi}(p), \hat{\omega}(p)] \exp [i(k x-\sigma t)]\},
$$

where the hat denotes Fourier transformed variables, $k$ is the zonal wavenumber, and $\sigma$ is the wave frequency. The nondimensionalized $\omega$ and potential vorticity (PV) equations can then be expressed as

$$
\frac{d^{2} \hat{\omega}}{d p^{2}}-S k^{2} \hat{\omega}=i 2 \lambda k^{3} \hat{\psi}+k^{2} \hat{Q}
$$

and

$$
(\bar{u} k-\sigma)\left(\frac{d^{2} \hat{\psi}}{d p^{2}}-S k^{2} \hat{\psi}\right)=i \frac{d \hat{Q}}{d p},
$$

where $Q=Q_{\mathrm{lh}}+Q_{\mathrm{sf}}$ is the diabatic heating rate divided by pressure, representing both latent heating $Q_{\mathrm{lh}}$ and heating associated with surface sensible heat fluxes $Q_{\mathrm{sf}}, S$ is the basic-state static stability as defined in HS19, $\lambda$ is the basicstate vertical wind shear, and $\bar{u}(p)=\lambda\left(p_{b}-p\right)+u_{0}$ is the basic-state zonal wind (arrows in Fig. 1a). The set of equations is completed with the boundary conditions $\hat{\omega}=0$ at $p_{t}$ and $p_{b}$ together with the thermodynamic equation

$$
(\bar{u} k-\sigma) \frac{d \hat{\psi}}{d p}+i \hat{Q}+\lambda k \hat{\psi}=0 \quad \text { at } \quad p=p_{t}, p_{b}
$$

where $p_{t}$ and $p_{b}$ are the pressure at the top and bottom of the domain, respectively.
For simplicity, we assume constant $S$ and $\lambda$. Note that Mak (1998) prescribed $S$ as a step function with a smaller value in the lowest layer. Our choice of a constant $S$ is based on the argument that in the presence of latent heating, the effective static stability not only reduces in the surface flux layer but also in the latent heating layer where parcel displacements are nearly moist adiabatic (HS19). Furthermore, the effect of reduced stratification related to moist processes and surface fluxes is incorporated partially through the diabatic heating (see HS19 for further clarification). Following HS19, we refer to $d \psi / d p$, which is proportional to the negative density perturbation, as temperature, and choose representable model parameters for large-scale midlatitude flow (see Table 1). The only difference from Mak (1994) and HS19 is a uniform increase of $\bar{u}$ by $u_{0}=4 \mathrm{~m} \mathrm{~s}^{-1}$, consistent with the surface flux implementation introduced by Mak (1998), whereas the differences from Mak (1998) are in $S$ (as noted above), $\lambda$, and $p_{t}$.

\section{b. Parameterization of latent heating}

Following Mak (1994), latent heating divided by pressure is proportional to upward motion at the bottom of the latent heating layer and is parameterized as

$$
\hat{Q}_{\mathrm{lh}}=-\frac{\varepsilon_{\mathrm{lh}} h_{\mathrm{lh}}(p)}{2} \hat{\omega}_{*}(k)
$$

TABLE 1. Nondimensional values of model parameters. Value from HS19 (Mak 1998) is indicated in parentheses (square brackets) if different from this study. See Mak (1998) for a detailed description of $S$.

\begin{tabular}{ccccccc}
\hline \hline Parameter & $S$ & $\lambda$ & $u_{0}$ & $f$ & $p_{t}$ \\
\hline Nondimensional value & $4[*]$ & $3.5[5.0]$ & $0.4(0.0)$ & 1 & $0.15[0.0]$ & 1 \\
\hline
\end{tabular}


TABLE 2. Values of nondimensional surface flux intensity parameter $\left(\varepsilon_{\mathrm{sf}}\right)$ and respective units for different surface flux parameterizations.

\begin{tabular}{|c|c|c|c|c|c|c|}
\hline Surface flux parameterization & $T_{s}$ & $v_{s}$ & $\omega_{*, 0^{\circ}}$ & $\omega_{*,-90^{\circ}}$ & $\omega_{*,+90^{\circ}}$ & $\omega_{*, 180^{\circ}}$ \\
\hline$\varepsilon_{\mathrm{sf}}($ nondimensional) & 1.5 & 1.4 & 3.12 & 3.12 & -3.12 & -3.12 \\
\hline Units of dimensional $\varepsilon_{\mathrm{sf}}$ & $\mathrm{KPa} \mathrm{m}^{-2}$ & $\mathrm{~K} \mathrm{~m}^{-1}$ & $\mathrm{KPa}^{-1}$ & $\mathrm{KPa}^{-1}$ & $\mathrm{KPa}^{-1}$ & $\mathrm{KPa}^{-1}$ \\
\hline
\end{tabular}

where $\varepsilon_{\mathrm{lh}}$ is the latent heating intensity parameter, $\omega_{*}$ is the vertical motion at the bottom of the latent heating layer, and $h_{\mathrm{lh}}$ is the vertical profile of latent heating $d i$ vided by pressure. Consistent with Mak (1994) we let

$$
\begin{aligned}
h_{\mathrm{lh}}(p) & =H(p-0.4)-H(p-0.9) \\
& =\left\{\begin{array}{lll}
0 & \text { for } p<0.4 \text { and } p>0.9 \\
1 & \text { for } 0.4<p<0.9
\end{array},\right.
\end{aligned}
$$

where $p_{\mathrm{lht}}=0.4$ and $p_{\mathrm{lhb}}=p_{*}=0.9$ are the nondimensional pressure at the top and bottom of the latent heating layer, corresponding to 400 and $900 \mathrm{hPa}$, respectively. We have also tested other levels for the heating boundaries, which yield qualitatively similar results (not shown).

We use the same latent heating intensity parameter $\varepsilon_{\mathrm{lh}}=12.5$ for all experiments, which corresponds to a heating rate approaching $40 \mathrm{~K} \mathrm{day}^{-1}$ when $\omega \sim$ $10^{-3} \mathrm{hPa} \mathrm{s}^{-1}$. This choice is based on the arguments about reasonable heating rates by HS19, where similar heating rates yield qualitatively comparable results. Note that the heating should be viewed as heating anomalies rather than total heating.

\section{c. Parameterization of surface sensible heat fluxes}

\section{1) ForMulations MOTIVATED BY TEMPERATURE AND TEMPERATURE ADVECTION}

We apply the linearized version of the bulk relation for surface sensible heat fluxes from Monin-Obukhov theory

$$
Q_{\mathrm{sf}} \propto\left|\mathbf{v}_{s}\right|\left(\mathrm{SST}-T_{s}\right),
$$

where $\left|\mathbf{v}_{s}\right|$ is the surface wind speed, SST is the sea surface temperature, and $T_{s}$ is the temperature of the overlying air. Following Mak (1998), we assume a constant sea surface temperature and define the surface fluxes divided by pressure as

$$
\hat{Q}_{\mathrm{sf}, T}=\left.\varepsilon_{\mathrm{sf}} h_{\mathrm{sf}}(p) \frac{\partial \hat{\psi}}{\partial p}\right|_{s},
$$

where the subscript $s$ denotes a surface value and the impact of horizontal wind speed is incorporated in the intensity parameter $\varepsilon_{\text {sf }}$. This formulation does not, however, take into account that surface sensible heat fluxes are typically located where the meridional temperature advection $v_{s}(\partial \bar{T} / \partial y) \propto-i k \psi_{s} \lambda$ is anomalously strong (Boutle et al. 2010). Thus, we introduce an alternative formulation based on meridional wind anomalies:

$$
\hat{Q}_{\mathrm{sf}, v}=-\varepsilon_{\mathrm{sf}} h_{\mathrm{sf}}(p) i k \hat{\psi}_{s},
$$

where the basic-state meridional temperature gradient is incorporated in the intensity parameter $\varepsilon_{\text {sf }}$. Note that the dimensional form of the surface flux intensity parameter $\varepsilon_{\text {sf }}$ has different units in (8) and (9) (see Table 2).

The heating profile for surface fluxes $h_{\mathrm{sf}}$ is independent of the flux formulation and given by

$$
h_{\mathrm{sf}}(p)=H(p-0.9)=\left\{\begin{array}{lll}
0 & \text { for } & p<0.9 \\
1 & \text { for } & p>0.9
\end{array}\right.
$$

Note that interior PV anomalies for the given profiles of surface fluxes and latent heating in conjunction with constant $S$ and $\lambda$ can only exist at the two heating boundaries where $d Q / d p \neq 0$ (see dashed lines relative to the heating profiles in Fig. 1a).

\section{2) Formulation MOTIVATED BY SENSITIVITY TO HORIZONTAL LOCATION}

In addition to the surface flux formulations above, we introduce a third formulation based on $\omega_{*}$

$$
\hat{Q}_{\mathrm{sf}, \omega}=\varepsilon_{\mathrm{sf}} h_{\mathrm{sf}}(p) \hat{\omega}_{*}
$$

While this choice is not necessarily based on physical or observational arguments, it has the advantage that we can directly control the relative position between the surface fluxes and the latent heating, independent of potential alterations in the wave structure related to diabatic effects. As low-level upward motion is located near warmair advection, the surface fluxes based on this formulation are similar to the formulations based on temperature [see (8)] and meridional wind [see (9)] anomalies.

By including an imaginary part in the intensity parameter $\varepsilon_{\text {sf }}$, we phase shift $Q_{\text {sf }}=\operatorname{Re}\left\{\hat{Q}_{\text {sf }}(p) \exp [i(k x-\sigma t)]\right\}$ such that downward surface sensible heat fluxes are located upstream $\left(\operatorname{Im}\left\{\varepsilon_{\mathrm{sf}}\right\}>0\right)$ or downstream $\left(\operatorname{Im}\left\{\varepsilon_{\mathrm{sf}}\right\}<0\right)$ of the region of latent heating (see schematic in Fig. 1b for the relative location of the surface fluxes and Table 2 for the numerical value of $\varepsilon_{\mathrm{sf}}$ for the respective locations). 
This allows us to investigate how the relative positioning of surface sensible heat fluxes and latent heating changes the growth rate and the structure of the solution. Although we are shifting the surface fluxes from their typical location relative to the latent heating, such a sensitivity analysis helps us to better understand how alterations in the location of surface fluxes change the relative role of $\mathrm{PV}$ anomalies at different vertical levels and hence affect cyclone structure and development.

\section{3) SuRfaCE FLUX INTENSITY}

To ensure a fixed ratio between the maximum intensity of latent heating and surface sensible heat fluxes, i.e., $\max \left(Q_{\mathrm{lh}}\right) / \max \left(Q_{\mathrm{sf}}\right)$, across all experiments, we adjust the surface flux intensity parameter $\varepsilon_{\text {sf }}$ between experiments accordingly. This is necessary, because changes in the surface flux intensity can cause modifications in the structure that modify the relative strength of the surface fluxes compared to the amount of latent heating. A fixed ratio ensures that the relative intensity of surface fluxes is similar in the different experiments. The ratio is maintained across experiments by varying $\varepsilon_{\text {sf }}$ in a trial-and-error approach for each of the surface flux formulations.

We tested surface flux intensities that range from zero to intensities 3 times larger than the latent heating rate. As the surface flux intensity is highly dependent on various factors, e.g., the type of cyclone and differences in the sea surface temperature underneath a cyclone, it is difficult to define a universal intensity for the incipient stage of the cyclone. For example, surface sensible heat fluxes from composites along the frontal passage of 10 midlatitude cyclones ranged from about $-30 \mathrm{~W} \mathrm{~m}^{-2}$ in the warm sector to about $100 \mathrm{~W} \mathrm{~m}^{-2}$ in the cold sector (Persson et al. 2005), while the surface fluxes in a Met Office Unified Model analysis of a mature midlatitude cyclone were significantly stronger and ranged from $-100 \mathrm{~W} \mathrm{~m}^{-2}$ in the warm sector to $250 \mathrm{~W} \mathrm{~m}^{-2}$ in the cold sector (Sinclair et al. 2010).

Nevertheless, as our results are qualitatively similar for all investigated intensities, we restrict our presentation to heating rates associated with surface fluxes that reach $50 \%$ of the latent heating intensity, which corresponds to about $150 \mathrm{~W} \mathrm{~m}^{-2}$ when the surface fluxes affect the air column between 1000 and $900 \mathrm{hPa}$. The corresponding values of $\varepsilon_{\mathrm{sf}}$ are shown in Table 2 for all surface flux formulations used in this study. Choosing lower/higher intensities would result in a weaker/stronger effect by surface fluxes, but yield qualitatively similar results.

\section{d. Numerical method}

We apply a numerical solution technique, where (2)(4) form an eigenvalue problem that can be solved for the eigenvalue $\sigma$ and the eigenvectors $\hat{\psi}(p)$ and $\hat{\omega}(p)$ for a given wavenumber $k$. We use a resolution of 171 vertical levels and calculate solutions for 122 different wavenumbers. Further details can be found in HS19.

\section{e. Normalization of solution}

As the nontrivial solution of the eigenvalue problem formed by (2)-(4) contains at least 1 degree of freedom, we cannot compare $\psi$ and $\omega$ quantitatively for different experiments and wavelengths (see HS19 for further clarification). Consistent with HS19, we therefore normalize all variables with respect to the domain averaged total eddy energy and argue that such a scaling yields a sound basis for a robust and reliable intercomparison.

We assessed the validity of the QG approximation by comparing the scale of the QG terms in the momentum equations to the ageostrophic advection term. Consistent with HS19, we find that the ageostrophic term is less than $50 \%$ of the dominant QG terms when using a dimensional surface velocity of $5 \mathrm{~m} \mathrm{~s}^{-1}$ (not shown). We therefore argue that our linear QG framework is suitable to investigate the impact of different types of diabatic heating as long as we stay clear of the intensity threshold discussed by HS19, beyond which the diabatic component of $\omega$ dominates over the dynamic component.

\section{Impact of surface sensible heat fluxes on cyclone development}

We first focus on the surface flux formulations based on $T_{s}$ in (8) and $v_{s}$ in (9), followed by the formulation based on $\omega_{*}$ in (11), which includes the sensitivity experiments where we zonally shift the surface fluxes relative to the location of the latent heating. Given the limitations of the linear QG framework, this study mainly focuses on the incipient stage of cyclone development.

\section{a. Parameterizations using $T_{s}$ and $v_{s}$}

\section{1) GROWTH RATE}

The main modification of the dry Eady growth rate is due to the inclusion of latent heating, with the surface sensible heat fluxes only playing a minor role (Fig. 2). Including only surface sensible heat fluxes based on $T_{s}$ and $v_{s}$, without latent heating, introduces an additional mode with weakly positive growth rates (up to one-third of the maximum Eady growth rate) at shorter wavelengths, while growth rates at long wavelengths are almost unchanged compared to the dry Eady mode (not shown). As in Mak (1998), the growth rates at short wavelengths become similar to the Eady growth rates 


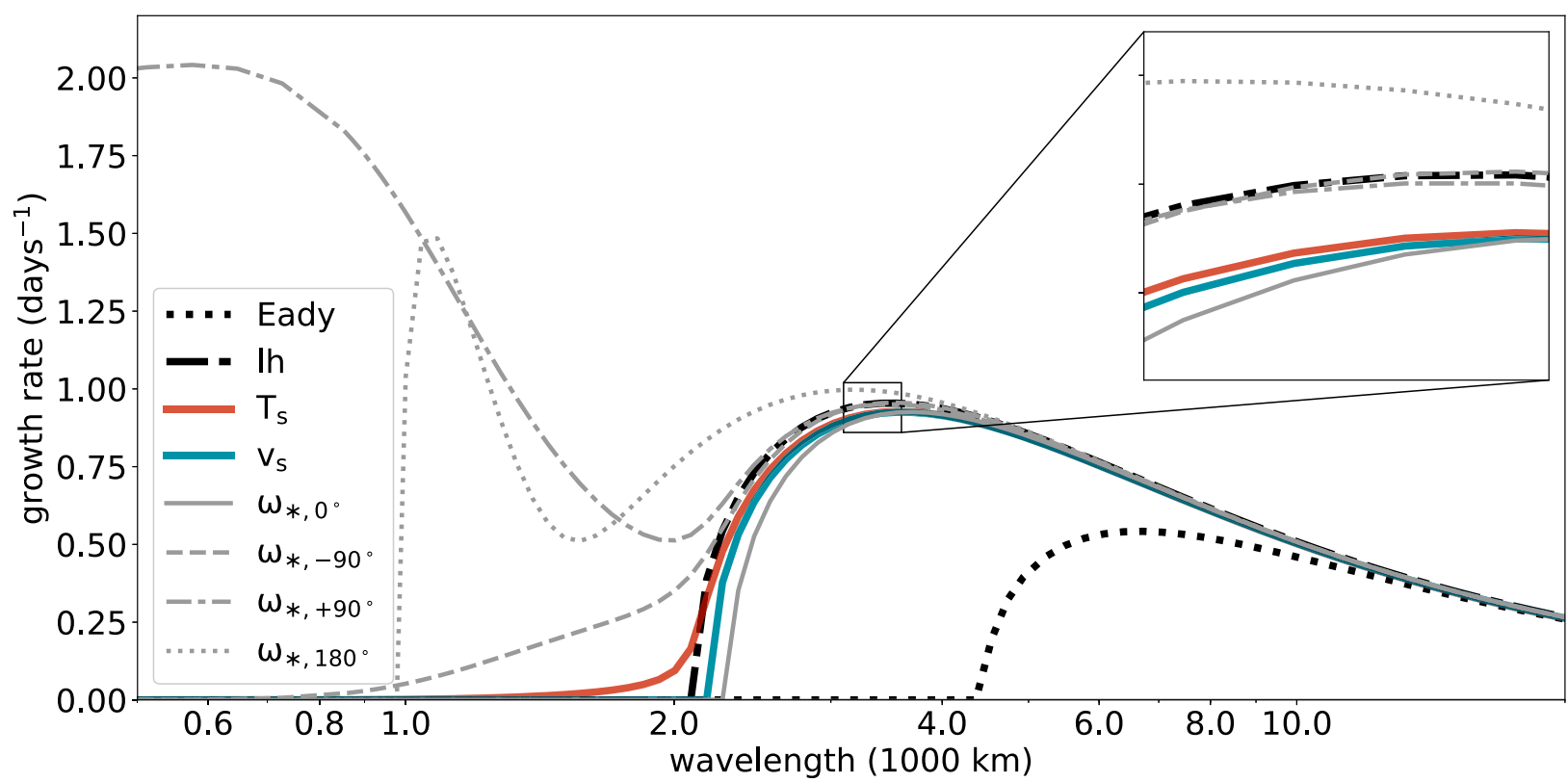

FIG. 2. Growth rate vs wavelength without diabatic heating (Eady, black dotted), with latent heating only (lh, black dot-dashed), as in HS19, and with latent heating and surface sensible heat fluxes, where the surface fluxes are formulated with respect to $T_{s}\left[(8)\right.$, red], $v_{s}[(9)$, blue], or $\omega_{*}$ [(11), gray]. The big box at the upper right shows a zoom-in of the area in the small box. The results for the surface fluxes formulated with respect to $\omega_{*}$ are shown for four different phase shifts. See text for further explanation.

when using Mak's (1998) discontinuous static stability profile (see section 2a). Surface fluxes in conjunction with latent heating reduce baroclinic growth (red and blue lines in Fig. 2), which is consistent with the destruction of eddy available potential energy and lowlevel baroclinicity by surface sensible heat fluxes.

\section{2) General structure of THE MOST UNSTABLE MODE}

Comparing the structure of temperature (shading), meridional wind (yellow contours), and latent heating (black contours) for the most unstable modes, the solutions with surface fluxes (Figs. 3c,d) bear great resemblance compared to the solution including latent heating only (Fig. 3b). The overall structure of these diabatically influenced solutions even remains qualitatively similar to the dry Eady solution (Fig. 3a). All experiments feature a baroclinically unstable structure, with the meridional wind, and hence the streamfunction, as well as the PV anomalies (position of extrema marked by gray dots), and vertical motion (not shown) tilting westward with height, while the temperature tilts eastward with height. Thus, all solutions are energetically consistent, with warm air ascending poleward.

The cooling from surface sensible heat fluxes (dashed gray contours in Figs. 3c,d) formulated with respect to temperature (meridional wind) is slightly upstream (downstream) of the area of upward motion and is hence located more or less directly below the area of latent heating.

\section{3) AMPLITUDE AND LOCATION OF POTENTIAL VORTICITY ANOMALIES}

Evaluating the terms in the PV equation, (3), we find that the maximum tendency from meridional advection of basic-state PV (rotated plus symbols in Fig. 3) is located less than $90^{\circ}$ upstream (downstream) of the upper (lower) positive boundary PV anomaly for all experiments. The positive tendencies contribute to both the exponential growth of the PV anomalies associated with the unstable wave solution as well as to the upstream (downstream) advection of the upper (lower) PV anomaly. This setup counteracts the advection by the basic-state zonal wind and ensures that the boundary PV anomalies are phase locked. Similarly, the maximum diabatic tendency (nonrotated plus symbols) at the heating boundaries is located less than $90^{\circ}$ upstream (downstream) of the upper (lower) diabatically induced positive PV anomaly, resulting in net amplification and propagation that ensures phase locking.

The cooling associated with the surface fluxes below the layer of latent heating increases the vertical heating gradient and hence, according to the PV equation, (3), the dominance of the diabatic PV anomaly at the bottom of the latent heating layer. At the surface, however, the downward surface fluxes induce a negative diabatic 

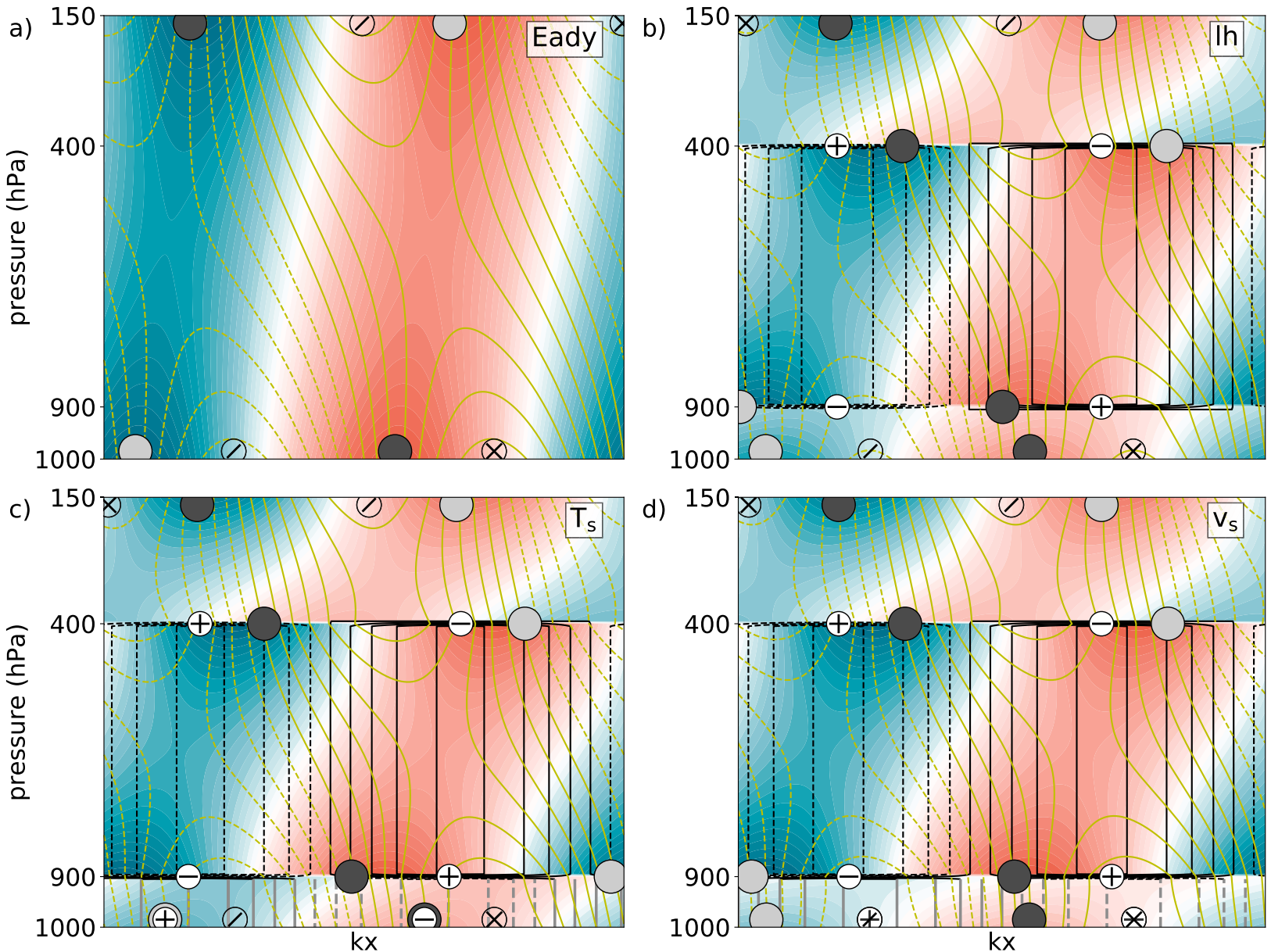

FIG. 3. Temperature (shading), meridional wind (yellow contours), latent heating (black contours), and heating from surface sensible heat fluxes (gray contours) for the most unstable solution (a) without diabatic heating (Eady), (b) with latent heating only (lh), and with latent heating and surface fluxes, where the surface fluxes are either formulated with respect to (c) $T_{s}$ or (d) $v_{s}$. Dark (light) gray dots show position of maximum (minimum) PV anomalies at the four interfaces. Plus and minus symbols show maxima and minima of PV tendency due to either diabatic forcing (nonrotated + and - symbols) or meridional advection of basic-state PV (rotated + and - symbols), respectively, which overlap at the surface in $(\mathrm{d})$.

PV anomaly that suppresses the existing surface PV anomaly. The contribution from the diabatic tendency associated with surface fluxes is therefore decreasing the dominance of the surface PV anomaly relative to the other PV anomalies.

The increasing dominance of the PV anomaly at the bottom of the latent heating layer relative to the surface PV anomaly is depicted in Fig. 4a, where the vertical integral of maximum $\mathrm{PV}$ across the bottom of the latent heating layer (red dots) becomes larger than the integral of maximum PV around the surface (black dots) when surface fluxes based on $T_{s}$ and $v_{s}$ are included. As a positive PV anomaly is associated with warm air above and cold air below (Hoskins et al. 1985), the decreased dominance of the surface PV anomaly relative to the PV anomaly at the bottom of the latent heating layer is consistent with a weakening of the positive temperature anomalies below $900 \mathrm{hPa}$ (Figs. 3c,d).

Although the diabatic PV tendency suppresses the surface PV anomaly, the positive contribution from meridional advection of basic-state PV dominates over the diabatic contribution (not shown), resulting in net amplification of the surface PV anomaly. The dominance of meridional advection also ensures that the surface PV anomaly remains phase locked and is advected downstream. This is even the case when the negative diabatic tendency is located downstream of the surface PV, opposing its downstream propagation, as in the formulation based on $v_{s}$ (Fig. 3d).

\section{4) COMPONENTS OF VERTICAL MOTION}

To study the impact of surface fluxes on vertical motion, we split $\omega$ into components due to the dynamic and 

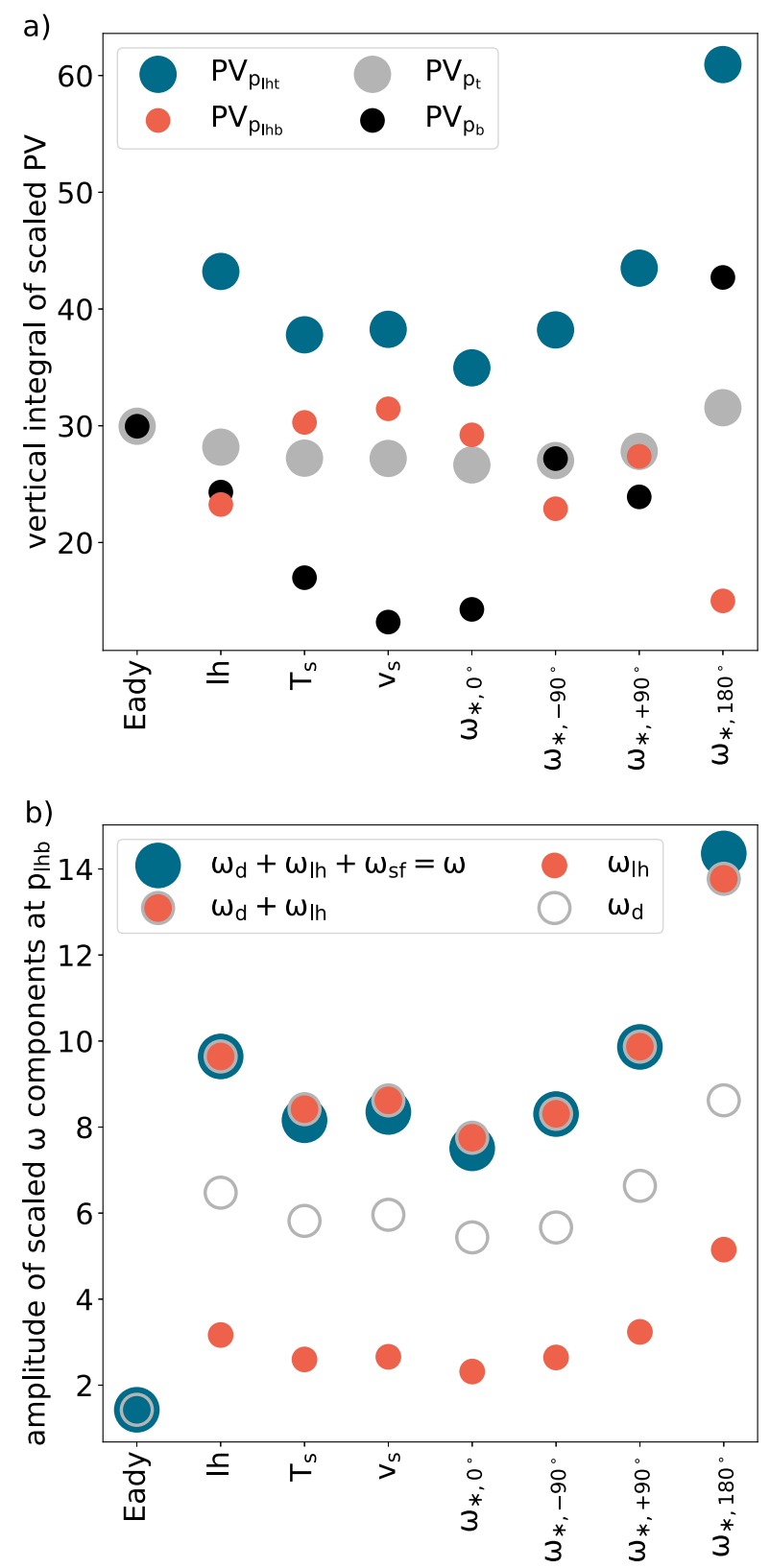

surface flux experiment

FIG. 4. (a) Vertical integral of the magnitude of scaled PV anomalies (proportional to the magnitude of the PV anomalies) at the model boundaries $p_{t}=0.15$ (gray) and $p_{b}=1.0$ (black) and the heating interfaces $p_{\mathrm{lht}}=0.4$ (blue) and $p_{\mathrm{lhb}}=0.9$ (red). (b) Amplitude of scaled components of $\omega_{*}$ at the bottom of the latent heating layer, where the subscripts $d$, lh, and sf denote dynamic, latent heating, and surface flux components, respectively. Results are shown for experiments without diabatic heating (Eady), latent heating only (lh), and for surface fluxes based on $T_{s}, v_{s}$, and $\omega_{*}$ (see text for further explanation). All solutions are scaled with respect to the total energy averaged over the domain. diabatic forcings on the right-hand side of the $\omega$ equation, (2) [see Mak (1994) and HS19 for further details].

Consistent with the low-level cooling by surface sensible heat fluxes around the area of upward motion and below the area of latent heating, the vertical velocity component due to the forcing by surface fluxes reduces the total vertical velocity (cf. blue dots with red dots enclosed by gray circles in Fig. 4b). Even though one has to be careful when comparing absolute vertical velocity magnitudes across experiments (see the normalization issue in section 2e), the weakening of the vertical velocity also causes a reduction in the latent heating component of the vertical velocity (red dots), as the latent heating is parameterized with $\omega_{*}$. As the dynamic component (gray circles) is enhanced in the presence of latent heating, it also diminishes when surface fluxes are included.

\section{5) ENERGETICS}

The effect of surface sensible heat fluxes on the energetics is investigated using the energy framework introduced by Lorenz (1955), where the tendency of domain-averaged eddy available potential energy $A_{e}$ is defined as

$$
\frac{\partial A_{e}}{\partial t}=C_{a}+G_{e}-C_{e}
$$

with

$C_{a}=-\frac{\lambda}{S} \overline{\psi_{x} \psi_{p}}, \quad G_{e}=-\frac{1}{S} \overline{Q \psi_{p}}, \quad$ and $\quad C_{e}=\overline{\omega \psi_{p}}$

representing the conversion from basic-state available potential energy to eddy available potential energy $\left(C_{a}\right)$, the generation of eddy available potential energy through diabatic heating $\left(G_{e}\right)$, and the conversion from eddy available potential energy to eddy kinetic energy $\left(C_{e}\right)$, respectively. The bar denotes zonal and vertical averages. We further split the diabatic term into components due to latent heating $G_{e}^{\mathrm{lh}}$ and surface fluxes $G_{e}^{\mathrm{sf}}$ using the respective heating rates $Q_{\mathrm{lh}}$ and $Q_{\mathrm{sf}}$. We define changes in $G_{e}^{\text {sf }}$ as direct effects of surface fluxes, while changes in $C_{a}, C_{e}$, and $G_{e}^{\mathrm{lh}}$ due to surface fluxes are referred to as indirect effects.

Comparing the different terms in the energy equation, (12), relative to the net source of eddy available potential energy $A_{e}$, we find a weak and negative contribution from $G_{e}^{\text {sf }}$ when surface fluxes are included (Fig. 5). This negative contribution is largest when the surface fluxes are based on surface temperature, because the downward surface fluxes are then more directly collocated with the low-level positive temperature anomalies (Fig. 3c).

The positive contribution from $G_{e}^{\mathrm{lh}}$ reduces when surface fluxes are included. This is consistent with the 


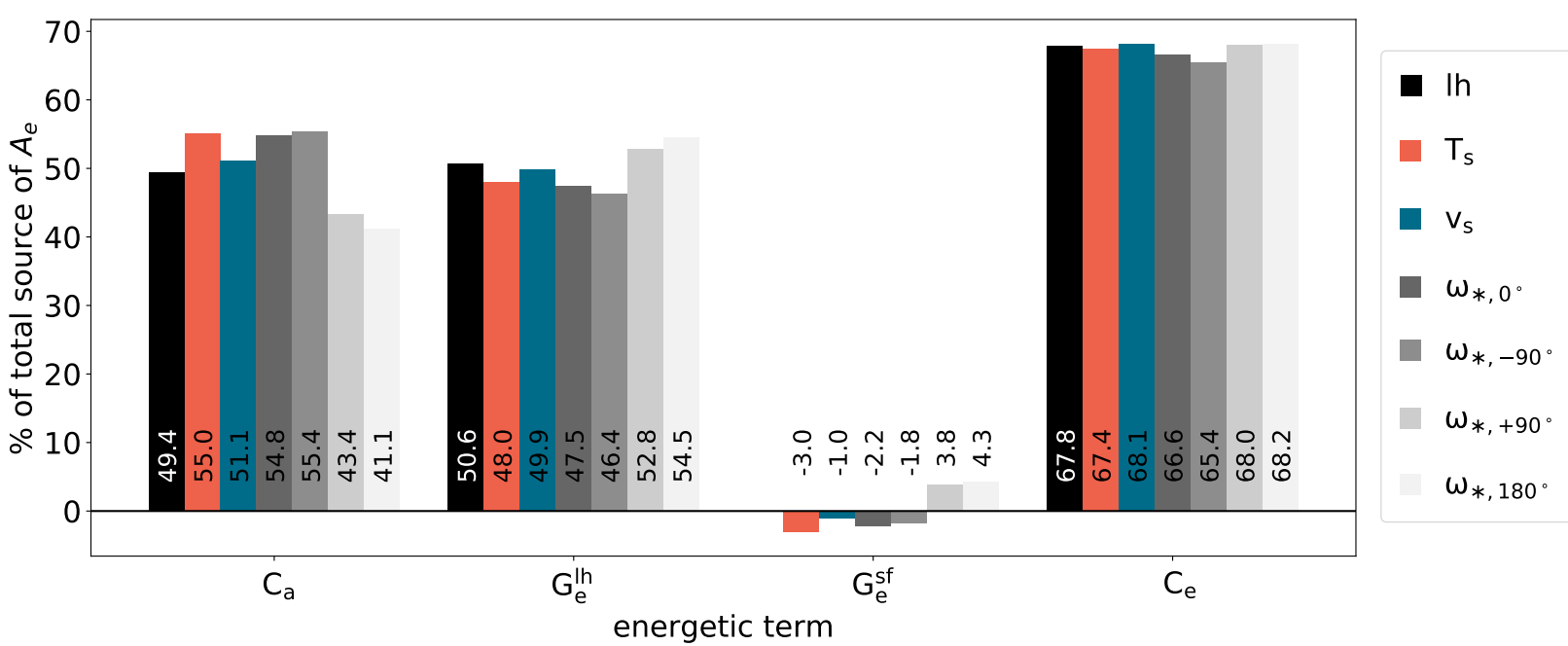

FIG. 5. Relative contributions from the energy terms for experiments with latent heating only (lh, black) and for surface fluxes based on $T_{s}$ (red), $v_{s}$ (blue), and $\omega_{*}$ (gray). Each term is scaled with respect to the total source of eddy available potential energy, i.e., $C_{a}+G_{e}^{\mathrm{lh}}+G_{e}^{\mathrm{sf}}$.

reduced vertical velocity, and hence latent heating, caused by the downward surface fluxes underneath the region of ascent discussed above. Furthermore, as latent heating is associated with enhanced baroclinic growth, a weakening of latent heating by surface fluxes is in agreement with the decrease in growth rate when surface fluxes are added (Fig. 2).

The contribution from $C_{a}$ increases when surface fluxes are included. This is consistent with a downstream shift of the temperature field in the surface flux layer (Figs. 3c,d), which better collocates the positive temperature anomalies with the northward flow, thereby increasing the meridional heat flux.

The contributions from $C_{e}$ barely change when surface fluxes are included. This can be explained by the combination of a decrease in $C_{e}$ due to the reduction in vertical velocity associated with surface fluxes and an increase in $C_{e}$ due to the downstream shift in the low-level temperature field that better collocates the positive temperature anomalies with upward motion. The net effect on $C_{e}$ is therefore either weakly negative (when fluxes are based on $T_{s}$ ) or weakly positive (when fluxes are based on $v_{s}$ ).

\section{b. Parameterizations using $\omega_{*}$ including phase shifts}

When downward surface sensible heat fluxes are proportional to upward motion at the bottom of the latent heating layer, the location of the surface fluxes and the PV anomalies (Fig. 6a) is between the corresponding locations when surface fluxes are based on temperature (Fig. 3c) and meridional wind (Fig. 3d). The maximum growth rate (gray solid line in Fig. 2) and the amplitude of the PV anomalies as well as the vertical velocity components (Fig. 4) are comparable to the corresponding growth rates and amplitudes for the surface flux formulations based on surface temperature and meridional wind.

\section{1) SURFACE FLUXES SHIFTED $180^{\circ}$}

When we shift upward surface fluxes in phase with upward motion, and hence latent heating (cf. black and gray contours in Fig. $6 \mathrm{~d}$ ), the growth rate (dotted gray line in Fig. 2) of the deep mode at long wavelengths $(\geq 2000 \mathrm{~km})$ is larger than in all other experiments. The increased growth rate is consistent with a strengthening of the vertical velocity by surface fluxes (cf. blue dots with red dots enclosed by gray circles in Fig. 4b), as well as an increase in the generation of eddy available potential energy by latent heating and surface fluxes (lightest gray bars in Fig. 5).

The zonal collocation of upward surface sensible heat fluxes and latent heating reduces the vertical heating gradient at the bottom of the heating layer and hence the dominance of the PV anomaly at this level relative to the other PV anomalies (Fig. 4a). On the other hand, the relative dominance of the surface PV anomaly is enhanced with this surface flux configuration, because the positive diabatic PV tendency (nonrotated plus symbol in Fig. 6d) at the surface is located near the surface PV anomaly. This results in a stronger surface PV anomaly compared to the PV anomaly at the bottom of the latent heating layer, in contrast to the previous surface flux formulations.

\section{2) SURFACE FLUXES SHIFTED $\pm 90^{\circ}$}

When surface fluxes are shifted $90^{\circ}$ upstream (downstream), upward surface fluxes are located at the leading (trailing) edge of the warm sector (cf. black and gray contours in Figs. 6b,c). For both of these formulations, 

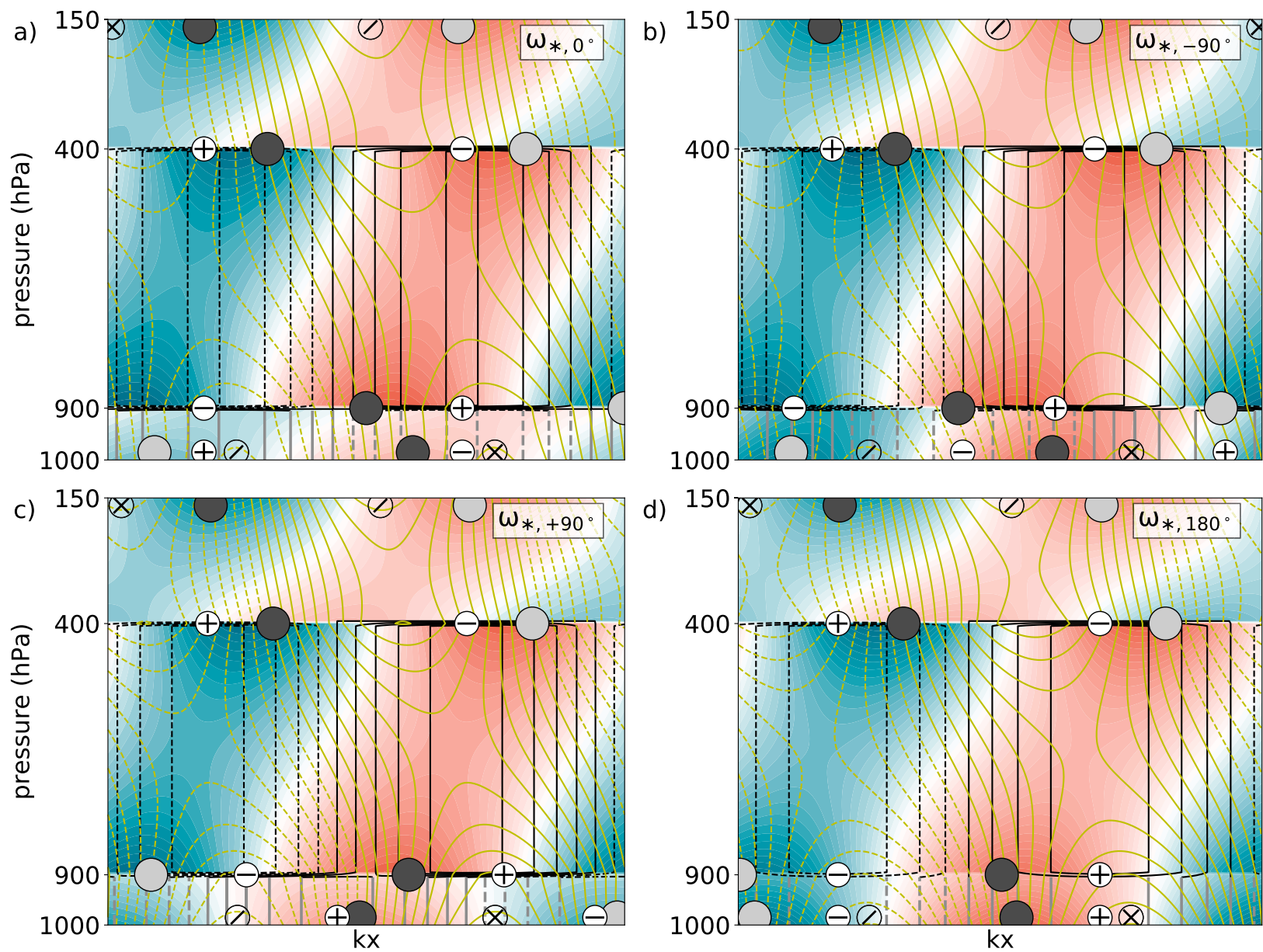

FIG. 6. As in Fig. 3, but for surface fluxes formulated with respect to $\omega_{*}$. Downward surface fluxes are (a) $0^{\circ},\left(\right.$ b) $-90^{\circ},\left(\right.$ c) $+90^{\circ}$, and (d) $180^{\circ}$ out of phase with upward motion.

the maximum growth rate (gray dashed and dot-dashed lines in Fig. 2) is, at long wavelengths, comparable to when no surface fluxes are included (black dashed line), and surface fluxes are neither enhancing nor suppressing the vertical velocity (cf. blue dots with red dots enclosed by gray circles in Fig. 4b).

Despite the similar growth rates and vertical velocities, these surface flux formulations are associated with a different low-level structure of temperature and PV (Figs. 6b,c). When the downward surface fluxes are shifted upstream of the latent heating, the surface fluxes are less out of phase with temperature compared to when the downward fluxes are located directly below the area of latent heating (Figs. 6a,b). The negative contribution from $G_{e}^{\text {sf }}$ is therefore slightly weaker (Fig. 5). Concurrently, the low-level temperature anomalies become stronger, in accordance with a slightly larger contribution from $C_{a}$. The increase in $G_{e}^{\text {sf }}$ and $C_{a}$ is associated with a slightly weaker contribution from $G_{e}^{\mathrm{lh}}$ and $C_{e}$ relative to the net source of $A_{e}$.
In contrast to the upstream shift of surface fluxes, a downstream shift results in an upstream displacement of the low-level temperature field, such that warm air collocates with heating from the surface fluxes (Fig. 6c). The contribution from $G_{e}^{\mathrm{sf}}$ is therefore positive (Fig. 5). Concurrently, the shift in temperature results in a reduced collocation between temperature and meridional wind at low levels, yielding a decrease in $C_{a}$ and hence $A_{e}$. Thus, the decrease in $C_{a}$ is associated with an increase in the contribution from $G_{e}^{\mathrm{th}}$ and $C_{e}$ relative to the net source of $A_{e}$.

Consistent with the upstream (downstream) shift in surface fluxes, there is an upstream (downstream) shift in the maximum vertical gradient in diabatic heating and hence the PV anomaly at the bottom of the latent heating layer (gray dots in Figs. 6a-c). This displacement results in a less ideal westward tilt between the diabatically induced PV anomalies and a weaker dominance of the PV anomaly at the bottom of the latent heating layer relative to the other PV anomalies (Fig. 4a). 
At the surface, the upstream shift in surface fluxes shifts the negative diabatic PV tendency (nonrotated symbols in Fig. 6) upstream and further away from the surface PV anomaly compared to when the downward surface fluxes are located directly below the area of latent heating. With the negative impact from the diabatic PV tendency being reduced, the surface PV anomaly becomes more dominant relative to the other PV anomalies (Fig. 4a).

As mentioned above, the downstream shift of surface fluxes is associated with an upstream shift in temperature, which is per definition also shifting the surface PV anomaly upstream (Hoskins et al. 1985). The surface PV anomaly is now farther away from the positive PV tendency associated with meridional advection (rotated symbols in Fig. 6), but almost entirely in phase with the diabatic PV tendency, which is in contrast to the other surface flux formulations. The positive contribution from the diabatic PV tendency strengthens the relative dominance of the surface PV anomaly compared to when the downward surface fluxes are located directly below the area of latent heating (Fig. 4a).

The upstream (downstream) displacement of the PV anomaly at the surface (bottom of the latent heating layer) associated with the downstream shift of the surface fluxes results in an eastward tilt with height between the low-level PV anomalies (Fig. 6c). Although an eastward tilt is not beneficial for baroclinic instability, both low-level PV anomalies remain phase locked with similar magnitudes (cf. red and black dots in Fig. 4a). This is most likely due to a strong impact of the upperlevel PV anomaly on the surface PV anomaly. These anomalies feature the typical westward tilt with height and thereby favor baroclinic development.

\section{3) Additional modes}

Additional unstable modes exist for two of the phaseshifted surface flux formulations at wavelengths shorter than $2000 \mathrm{~km}$ (dotted and dot-dashed lines in Fig. 2). However, we argue that these modes are unphysical, because the dynamic component of the vertical velocity is much smaller than its diabatic component (not shown), which indicates that these solutions are not reasonable for typical midlatitude cyclones (HS19). With a horizontal scale in the meso- $\alpha$ range, we also argue that these modes are probably too small to be reasonably resolved in the QG framework at hand. Nevertheless, as this is an idealized study that aims to broaden our understanding of moist baroclinic modes, we briefly discuss and contextualize these modes below.

The structure of the unstable mode corresponding to the $\omega_{*, 180^{\circ}}$ experiment at around $1000-\mathrm{km}$ wavelength is mainly around the top of the latent heating layer and does not feature any surface cyclone, whereas the structure corresponding to the $\omega_{*,+90^{\circ}}$ experiment at around $600-\mathrm{km}$ wavelength is shallow and mainly within the surface flux layer, where it tilts eastward with height (not shown). Neither of these additional modes bear resemblance to real cyclones nor to the additional mode at short wavelengths presented in the related surface flux study by Mak (1998), where the structure is tilting westward with height in the surface flux layer.

The absence of Mak's (1998) low-level mode is related to the inclusion of latent heating and the lack of a vertically varying static stability. As explained in section 2a, we argue that the static stability profile presented by Mak (1998) is not representative for this study when latent heating is included. Consequently, we do not recover Mak's (1998) low-level mode.

While Mak (1998) argued that his low-level mode resembles the structure of polar lows, HS19 questioned if such a low-level mode is physical, as the interacting PV anomalies are situated at the bottom and top of the mixed boundary layer, rendering their interactions questionable. To further test the model's capability to represent polar lows, we conducted additional experiments with a more representative polar low environment, where the tropopause was lowered from 150 to $500 \mathrm{hPa}$ and the Coriolis parameter $f$ was increased from 1.0 to 1.4 (corresponding to a latitude of $74^{\circ} \mathrm{N}$ ). Accordingly, the top of the latent heating layer was also lowered from 400 to $600 \mathrm{hPa}$. The main outcome is that the growth rates increase and shift to shorter wavelengths mainly around 1000-2000 km (not shown). These modifications are mainly due to the increase in Coriolis parameter and to the shallower latent heating layer, with the lowering of the tropopause playing a minor role. The corresponding structures are similar to the original structures in Figs. 3 and 6, though the lower tropopause consistently makes the deep modes shallower (not shown) and thereby remarkably similar to the structure of the idealized polar lows in Terpstra et al. (2015, their Fig. 5b). This confirms the hypothesis of Terpstra et al. (2015) that the development of polar lows resembles that of moist midlatitude cyclones with a lowered tropopause, alongside potential modifications by surface fluxes.

\section{Impact of surface latent heat fluxes and moisture supply}

While we are able to directly include the role of surface sensible heat fluxes in our model, we investigate the impact of surface latent heat fluxes indirectly by keeping $\varepsilon_{\text {sf }}$ the same as in Table 2 while increasing the latent heating intensity parameter $\varepsilon_{\mathrm{lh}}$ from its default value of 
12.5 to the intensity needed to match the growth rate of the experiment only including latent heating (Fig. 2). The resulting change of $\varepsilon_{\mathrm{lh}}$ is then inserted into (5) to estimate the corresponding average dimensional change in latent heating $\Delta \bar{Q}$ for a vertical velocity scaling of $10^{-3} \mathrm{hPa} \mathrm{s}^{-1}$ (Table 3). Assuming pseudoadiabatic ascent, the corresponding additional water vapor supply equals the average change in saturation humidity mixing ratio $\bar{q}_{s}$

$$
\frac{d \bar{q}_{s}}{d t}=-\frac{c}{L} \Delta \bar{Q}
$$

where $c_{p}$ is the heat capacity at constant pressure and $L$ is the latent heat of condensation. The additional water supply can then be used to estimate the required sustained surface latent heat flux to alter the air parcels accordingly:

$$
Q_{\mathrm{lf}}=L \frac{d \bar{q}_{s}}{d t} \frac{p_{\mathrm{lht}}-p_{\mathrm{lhb}}}{g}=-c_{p} \frac{p_{\mathrm{lht}}-p_{\mathrm{lhb}}}{g} \Delta \bar{Q},
$$

where $\left(p_{\mathrm{lhb}}-p_{\mathrm{lht}}\right) / g$ represents the mass of the heating layer, with $g$ being the gravitational constant.

For surface flux formulations based on surface temperature, meridional wind, and vertical motion at the bottom of the latent heating layer, where the maximum growth rate reduces compared to when no surface fluxes are included, the estimated intensity of sustained surface latent heat fluxes required to overcome the detrimental effects range from 36 to $43 \mathrm{Wm}^{-2}$ (Table 3). These values are small compared to the passage of midlatitude cyclones, where surface latent heat fluxes range from 30 to $140 \mathrm{~W} \mathrm{~m}^{-2}$ in the warm sector and even reach up to $200 \mathrm{~W} \mathrm{~m}^{-2}$ further ahead of the warm sector (Persson et al. 2005). We therefore argue that the moisture input from surface latent heat fluxes into the warm conveyor belt increases the latent heat release sufficiently to compensate for the detrimental effects of surface sensible heat fluxes, such that the net effect of surface sensible and latent heat fluxes is beneficial for cyclone development.

\section{Concluding remarks}

We included surface sensible heat fluxes in conjunction with moderate latent heating in the linear QG Eady (1949) model to investigate the direct and indirect effects of surface fluxes on the incipient stage of midlatitude cyclone development, where direct and indirect are defined as either directly influencing the diabatic generation of eddy available potential energy or related to indirect changes in the circulation and latent heating that affect the energetics, respectively. We find that
TABLE 3. Estimated changes of the latent heating intensity parameter $\left(\varepsilon_{\mathrm{lh}}\right)$ and latent heating $\left(Q_{\mathrm{lh}}\right)$ as well as sustained surface latent heat fluxes (SSLH) necessary to overcome the detrimental effects of surface sensible heat fluxes for the deep modes at long wavelengths in Fig. 2.

\begin{tabular}{lccc}
\hline \hline Surface flux parameterization & $T_{s}$ & $v_{s}$ & $\omega_{*, 0^{\circ}}$ \\
\hline$\Delta \varepsilon_{\mathrm{lh}}($ nondimensional $)$ & 0.31 & 0.34 & 0.37 \\
$\Delta Q_{\mathrm{lh}}\left(\mathrm{K} \mathrm{day}^{-1}\right)$ & 0.61 & 0.67 & 0.72 \\
SSLH $\left(\mathrm{W} \mathrm{m}^{-2}\right)$ & 36 & 39 & 43 \\
\hline
\end{tabular}

changes in the growth rate and structure due to surface sensible heat fluxes are rather small compared to changes related to latent heating. Growth rates reduce when downward surface sensible heat fluxes are located around warm surface air, poleward surface winds, or low-level ascent. This is expected from the decrease in low-level baroclinicity, where surface sensible heat fluxes cool (heat) the warm (cold) sector. The surface fluxes also yield a weakening of vertical motion and thus latent heat release, which also leads to a reduction in growth rate.

We tested different parameterizations to represent surface sensible heat fluxes and found that the results are more sensitive to the actual location of the surface sensible heat fluxes than to the type of surface flux parameterization. When upward surface sensible heat fluxes are located directly below the layer of latent heating, the growth rate increases. However, when the surface sensible heat fluxes are located one-quarter wavelength up- or downstream from the region of latent heating, the maximum growth rate is almost unaffected compared to the experiment with latent heating only.

The structure of the most unstable mode for all experiments is generally consistent with the energetics of baroclinic instability, featuring a QG streamfunction, meridional wind, PV anomalies, and vertical motion tilting westward with height as well as a temperature field tilting eastward with height. Surface sensible heat fluxes modify the relative role of the low-level PV anomalies by shifting the low-level temperature structure. When downward surface sensible heat fluxes are located below the equivalent of the warm conveyor belt, the diabatically induced PV anomaly at the bottom of the latent heating layer becomes more dominant than the PV anomalies at the model boundaries. This is consistent with enhanced vertical heating gradients at the interface between the layers of latent heating and surface fluxes.

In contrast, when upward surface sensible heat fluxes are located below the area of latent heating, the diabatic PV anomaly at the interface between the layers of latent heating and surface fluxes becomes the least dominant PV anomaly, while the surface PV anomaly becomes 
more dominant due to a positive diabatic PV tendency at the surface. Moreover, when downward surface sensible heat fluxes are located upstream or downstream of the area of latent heating, the diabatically induced PV anomaly at the bottom of the latent heating layer is shifted accordingly, resulting in a weaker or stronger westward tilt with height relative to the diabatic PV anomaly at the top of the layer of latent heating. Such a setup is less ideal for baroclinic development. Concurrently, the diabatic PV tendency around the surface PV anomaly is less negative-or even positive-compared to when downward surface sensible heat fluxes are located below the layer of latent heating. Consequently, the importance of the surface PV anomaly is similar to the diabatic PV anomaly at the bottom of the latent heating layer.

When downward surface sensible heat fluxes are located near the warm conveyor belt, the collocation of warm air with northward flow is improved, resulting in a positive impact on the conversion from basic-state available potential energy to eddy available potential energy. In contrast, the direct and indirect effects on the diabatic generation of eddy available potential energy are detrimental, where the indirect effect is related to a reduction in vertical motion and hence latent heating. Despite the reduction in vertical motion, the conversion from eddy available potential energy to eddy kinetic energy is, however, not significantly affected by surface fluxes.

The impact on the energetics described in the previous paragraph is qualitatively identical when surface sensible heat fluxes are shifted a quarter wavelength upstream. However, when the downward surface sensible heat fluxes are located one-quarter wavelength downstream, as well as when they are completely out of phase with latent heating, the qualitative impact on the energetics reverses, with a positive impact on the diabatic generation of eddy available potential energy and a negative impact on the conversion from basicstate available potential energy to eddy available potential energy. Hence, while the upstream and downstream shift of surface fluxes may result in similar growth rates, the low-level structure and energetics are quite different, which is potentially important for other aspects of the development, such as nonlinear processes. In general, our surface flux formulations yield a reduced strength in vertical motion at the bottom of the latent heating layer, except when the surface fluxes are reversed or shifted downstream, in which case the vertical motion at the bottom of the latent heating layer strengthens. However, similar to the other formulations, the modification of vertical motion does not significantly affect the conversion from eddy available potential energy to eddy kinetic energy.
When we simultaneously lower the tropopause, increase the Coriolis parameter, and make the latent heating layer shallower to better represent polar environments, our results are qualitative similar, though growth rates increase and unstable modes shift toward shorter wavelengths. Furthermore, consistent with a shallower troposphere, the structure of the unstable modes becomes shallower and thereby more similar to polar lows, supporting earlier findings that polar lows grow through moist baroclinic instability.

While our model framework only allows for a direct investigation of surface sensible heat fluxes, estimated modifications in moisture supply related to changes in latent heating indicate that the detrimental effects of the surface sensible heat fluxes are easily compensated by the indirect effect of providing additional moisture into the warm conveyor belt through surface latent heat fluxes. This finding further highlights the importance of previously identified moisture pathways into the warm conveyor belt (Boutle et al. 2010; Pfahl et al. 2014; Dacre et al. 2019), whereas local surface fluxes in the cold sector energetically do not appear to be a viable option. The moisture pathways into the warm conveyor belt and their connection to local and remote surface fluxes should thus be studied further using more complex models that are able to represent peripheral moisture sources from preceding cyclones or from moist air masses originating in the subtropics.

Acknowledgments. We are grateful to Michael Reeder for valuable comments and discussions and thank the three anonymous reviewers for their comments which helped to improve the paper. This work was supported by the Research Council of Norway funded project UNPACC (NFR Project 262220).

\section{REFERENCES}

Atlas, R., 1987: The role of oceanic fluxes and initial data in the numerical prediction of an intense coastal storm. Dyn. Atmos. Oceans, 10, 359-388, https://doi.org/10.1016/03770265(87)90025-X.

Balasubramanian, G., and M. Yau, 1996: The life cycle of a simulated marine cyclone: Energetics and PV diagnostics. J. Atmos. Sci., 53, 639-653, https://doi.org/10.1175/1520-0469(1996)053<0639: TLCOAS $>2.0$. CO;2.

Booth, J. F., L. Thompson, J. Patoux, and K. A. Kelly, 2012: Sensitivity of midlatitude storm intensification to perturbations in the sea surface temperature near the Gulf Stream. Mon. Wea. Rev., 140, 1241-1256, https://doi.org/10.1175/MWR-D-11-00195.1.

Bosart, L. F., 1981: The Presidents' Day snowstorm of 18-19 February 1979: A subsynoptic-scale event. Mon. Wea. Rev., 109, 1542-1566, https://doi.org/10.1175/1520-0493(1981)109<1542: TPDSOF $>2.0 . \mathrm{CO} ; 2$.

Boutle, I., R. Beare, S. Belcher, A. Brown, and R. Plant, 2010: The moist boundary layer under a mid-latitude weather system. 
Bound.-Layer Meteor., 134, 367-386, https://doi.org/10.1007/ s10546-009-9452-9.

Branscome, L. E., W. J. Gutowski Jr., and D. A. Stewart, 1989: Effect of surface fluxes on the nonlinear development of baroclinic waves. J. Atmos. Sci., 46, 460-475, https://doi.org/ 10.1175/1520-0469(1989)046<0460:EOSFOT >2.0.CO;2.

Browning, K. A., 1990: Organization of clouds and precipitation in extratropical cyclones. Extratropical Cyclones: Erik Palmén Memorial Volume, C. W. Newton and E. O. Holopainen, Eds., Amer. Meteor. Soc., 129-153.

Carrera, M. L., J. R. Gyakum, and D.-L. Zhang, 1999: A numerical case study of secondary marine cyclogenesis sensitivity to initial error and varying physical processes. Mon. Wea. Rev., 127, 641-660, https://doi.org/10.1175/ 1520-0493(1999)127<0641:ANCSOS>2.0.CO;2.

Craig, G., and H.-R. Cho, 1988: Cumulus heating and CISK in the extratropical atmosphere. Part I: Polar lows and comma clouds. J. Atmos. Sci., 45, 2622-2640, https://doi.org/10.1175/ 1520-0469(1988)045<2622:CHACIT>2.0.CO;2.

Dacre, H. F., O. Martinez-Alvarado, and C. O. Mbengue, 2019: Linking atmospheric rivers and warm conveyor belt airflows. J. Hydrometeor., 20, 1183-1196, https://doi.org/10.1175/JHMD-18-0175.1.

Danard, M. B., and G. E. Ellenton, 1980: Physical influences on East Coast cyclogenesis. Atmos.-Ocean, 18, 65-82, https:// doi.org/10.1080/07055900.1980.9649078.

Eady, E. T., 1949: Long-waves and cyclone waves. Tellus, 1 (3), 33-52, https://doi.org/10.3402/tellusa.v1i3.8507.

Fleagle, R. G., and W. A. Nuss, 1985: The distribution of surface fluxes and boundary layer divergence in midlatitude ocean storms. J. Atmos. Sci., 42, 784-799, https://doi.org/10.1175/ 1520-0469(1985)042<0784:TDOSFA $>2.0 . C O ; 2$.

Gutowski, W. J., Jr., and W. Jiang, 1998: Surface-flux regulation of the coupling between cumulus convection and baroclinic waves. J. Atmos. Sci., 55, 940-953, https://doi.org/10.1175/ 1520-0469(1998)055<0940:SFROTC $>2.0 . C O ; 2$.

Gyakum, J. R., and R. E. Danielson, 2000: Analysis of meteorological precursors to ordinary and explosive cyclogenesis in the western North Pacific. Mon. Wea. Rev., 128, 851-863, https://oi.org/ 10.1175/1520-0493(2000)128<0851:AOMPTO > 2.0.CO;2.

Haltiner, G., 1967: The effects of sensible heat exchange on the dynamics of baroclinic waves. Tellus, 19, 183-198, https:// doi.org/10.1111/j.2153-3490.1967.tb01472.x.

Haualand, K. F., and T. Spengler, 2019: How does latent cooling affect baroclinic development in an idealized framework? J. Atmos. Sci., 76, 2701-2714, https://doi.org/10.1175/JAS-D18-0372.1.

Hirata, H., R. Kawamura, M. Nonaka, and K. Tsuboki, 2019: Significant impact of heat supply from the Gulf Stream on a "superbomb" cyclone in January 2018. Geophys. Res. Lett., 46, 7718-7725, https://doi.org/10.1029/2019GL082995.

Hoskins, B., M. McIntyre, and W. Robertson, 1985: On the use and significance of isentropic potential vorticity maps. Quart. J. Roy. Meteor. Soc., 111, 877-946, https://doi.org/10.1002/ qj. 49711147002.

Jiang, W., and W. J. Gutowski, 2000: Moist baroclinic instability in the presence of surface-atmosphere coupling. J. Atmos. Sci., 57, 2923-2935, https://doi.org/10.1175/1520-0469(2000) 057<2923:MBIITP>2.0.CO;2.

Keeley, S., R. Sutton, and L. Shaffrey, 2012: The impact of North Atlantic sea surface temperature errors on the simulation of North Atlantic European region climate. Quart. J. Roy. Meteor. Soc., 138, 1774-1783, https://doi.org/10.1002/qj.1912.
Kuo, Y.-H., and R. J. Reed, 1988: Numerical simulation of an explosively deepening cyclone in the eastern Pacific. Mon. Wea. Rev., 116, 2081-2105, https://doi.org/10.1175/1520-0493(1988) 116<2081:NSOAED >2.0.CO;2.

_ and S. Low-Nam, 1990: Prediction of nine explosive cyclones over the western Atlantic Ocean with a regional model. Mon. Wea. Rev., 118, 3-25, https://doi.org/10.1175/1520-0493(1990) $118<0003$ :PONECO $>2.0 . \mathrm{CO} ; 2$.

_ fluxes during the early development and rapid intensification stages of seven explosive cyclones in the western Atlantic. Mon. Wea. Rev., 119, 457-476, https://doi.org/10.1175/15200493(1991)119<0457:EOSEFD>2.0.CO;2.

—, M. Shapiro, and E. G. Donall, 1991b: The interaction between baroclinic and diabatic processes in a numerical simulation of a rapidly intensifying extratropical marine cyclone. Mon. Wea. Rev., 119, 368-384, https://doi.org/10.1175/15200493(1991)119<0368:TIBBAD>2.0.CO;2.

Langland, R., R. Elsberry, and R. Errico, 1995: Evaluation of physical processes in an idealized extratropical cyclone using adjoint sensitivity. Quart. J. Roy. Meteor. Soc., 121, 1349-1386, https://doi.org/10.1002/qj.49712152608.

Lee, R., T. Woollings, and B. Hoskins, 2018: Impact of Gulf Stream SST biases on the global atmospheric circulation. Climate Dyn., 51, 3369-3387, https://doi.org/10.1007/s00382-018-4083-9.

Lorenz, E. N., 1955: Available potential energy and the maintenance of the general circulation. Tellus, 7, 157-167, https:// doi.org/10.3402/tellusa.v7i2.8796.

Mailhot, J., and C. Chouinard, 1989: Numerical forecasts of explosive winter storms: Sensitivity experiments with a meso- $\alpha$ scale model. Mon. Wea. Rev., 117, 1311-1343, https://doi.org/10.1175/1520-0493(1989)117<1311:NFOEWS> 2.0.CO;2.

Mak, M., 1994: Cyclogenesis in a conditionally unstable moist baroclinic atmosphere. Tellus, 46, 14-33, https://doi.org/10.3402/ tellusa.v46i1.15424.

- 1998: Influence of surface sensible heat flux on incipient marine cyclogenesis. J. Atmos. Sci., 55, 820-834, https://doi.org/10.1175/ 1520-0469(1998)055<0820:IOSSHF $>2.0$.CO;2.

Mullen, S. L., and D. P. Baumhefner, 1988: Sensitivity of numerical simulations of explosive oceanic cyclogenesis to changes in physical parameterizations. Mon. Wea. Rev., 116, 2289-2329, https://doi.org/10.1175/1520-0493(1988)116<2289:SONSOE > 2.0.CO;2.

Neiman, P. J., and M. Shapiro, 1993: The life cycle of an extratropical cyclone. Part I: Frontal-cyclone evolution and thermodynamic air-sea interaction. Mon. Wea. Rev., 121, 2153-2176, https://doi.org/10.1175/1520-0493(1993)121<2153: TLCOAE $>2.0 . C O ; 2$.

Nuss, W. A., and R. A. Anthes, 1987: A numerical investigation of low-level processes in rapid cyclogenesis. Mon. Wea. Rev., 115 , 2728-2743, https://doi.org/10.1175/1520-0493(1987)115<2728: ANIOLL $>2.0 . \mathrm{CO} ; 2$.

Persson, P. O. G., J. Hare, C. Fairall, and W. Otto, 2005: Air-sea interaction processes in warm and cold sectors of extratropical cyclonic storms observed during FASTEX. Quart. J. Roy. Meteor. Soc., 131, 877-912, https://doi.org/10.1256/ qj.03.181.

Pfahl, S., E. Madonna, M. Boettcher, H. Joos, and H. Wernli, 2014: Warm conveyor belts in the ERA-Interim dataset (1979-2010). Part II: Moisture origin and relevance for precipitation. J. Climate, 27, 27-40, https://doi.org/10.1175/ JCLI-D-13-00223.1. 
Reed, R. J., and M. D. Albright, 1986: A case study of explosive cyclogenesis in the eastern Pacific. Mon. Wea. Rev., 114, 2297-2319, https://doi.org/10.1175/1520-0493(1986)114<2297: ACSOEC $>2.0 . \mathrm{CO} ; 2$.

Schäfler, A., and Coauthors, 2018: The North Atlantic Waveguide and Downstream Impact Experiment. Bull. Amer. Meteor. Soc., 99, 1607-1637, https://doi.org/10.1175/BAMS-D-17-0003.1.

Sinclair, V. A., S. E. Belcher, and S. L. Gray, 2010: Synoptic controls on boundary layer characteristics. Bound.-Layer Meteor., 134, 387-409, https://doi.org/10.1007/s10546-009-9455-6.

Terpstra, A., T. Spengler, and R. W. Moore, 2015: Idealised simulations of polar low development in an Arctic moist baroclinic environment. Quart. J. Roy. Meteor. Soc., 141, 1987-1996, https://doi.org/10.1002/qj.2507.
Uccellini, L. W., R. A. Petersen, K. F. Brill, P. J. Kocin, and J. J. Tuccillo, 1987: Synergistic interactions between an upper-level jet streak and diabatic processes that influence the development of a low-level jet and a secondary coastal cyclone. Mon. Wea. Rev., 115, 2227-2261, https://doi.org/10.1175/1520-0493(1987) $115<2227:$ SIBAUL $>2.0$. CO 2 .

Zhang, D.-L., E. Radeva, and J. Gyakum, 1999: A family of frontal cyclones over the western Atlantic Ocean. Part II: Parameter studies. Mon. Wea. Rev., 127, 1745-1760, https://doi.org/10.1175/ 1520-0493(1999) $127<1745: \mathrm{AFOFCO}>2.0 . \mathrm{CO} ; 2$.

Zhang, Y., and P. H. Stone, 2011: Baroclinic adjustment in an atmosphere-ocean thermally coupled model: The role of the boundary layer processes. J. Atmos. Sci., 68, 2710-2730, https://doi.org/10.1175/JAS-D-11-078.1. 